\title{
The evolution of worker-queen polymorphism in Cataglyphis ants: interplay between individual- and colony-level selections
}

Fernando Amor \& Patrocinio Ortega \&

Michael J. Jowers \& Xim Cerdá \& Johan Billen \&

Alain Lenoir \& Raphaël R. Boulay

\begin{abstract}
In many ants, young queens disperse by flying away from their natal nest and found new colonies alone (independent colony founding, ICF). Alternatively, in some species, ICF was replaced by colony fission, in which young queens accompanied by workers found a new colony at walking distance from the mother nest. We compared the queen morphology of Cataglyphis floricola, which disperses by fission, with that of its most likely living ancestor, Cataglyphis emmae, which disperses by ICF. As in other species, the transition from ICF to fission is associated with queen miniaturization. Interestingly, C. floricola presents two types of small queens: brachypters (with short nonfunctional wings) and ergatoids (worker-like apterous queens). Ergatoids are, on average, $2.8 \mathrm{mg}$ lighter and have half the number of ovarioles than brachypters, which limits
\end{abstract}

Electronic supplementary material The online version of this article (doi:10.1007/s00265-011-1157-7) contains supplementary material, which is available to authorized users.

Communicated by L. Keller

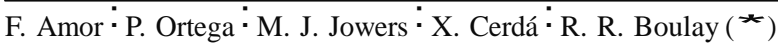
Estación Biológica de Doñana, CSIC,

Avenida Américo Vespucio s/n,

41092 Seville, Spain

e-mail: boulay@ebd.csic.es

J. Billen

Laboratory of Entomology, Zoological Institute, Leuven, Belgium

A. Lenoir

IRBI, UMR CNRS 6035, Université de Tours,

Tours, France

R. R. Boulay

Departamento de Biología Animal, Universidad de Granada, Granada, Spain the advantage for a colony to produce ergatoids instead of brachypters. Furthermore, more ergatoids are produced than brachypters, but their individual survival rate is lower. During colony fission, $96 \%$ of the cocoons containing brachypters but only $31 \%$ of those containing ergatoids are transferred to the daughter nests where, after emergence, they compete for becoming the next queen. The remaining queen cocoons, which stay in the mother queen's nest, are eliminated by workers upon emergence, probably to maintain monogyny. This waste of energy suggests that producing ergatoids instead of brachypters is unlikely to increase colony efficiency. We argue that the evolution of ergatoids could derive from a selfish larval strategy, developing into worker-like queens in spite of the colony interest.

Keywords Queen morphology · Dispersal · Levels of selection · Selfish strategy · Caste fate conflict

Introduction

Dispersal is an important biological phenomenon, involved in both species persistence and evolution (Clobert et al. 2001; Bullock et al. 2002). The benefits of dispersal include inbreeding avoidance, the colonization of favorable environments, and a decrease in local mate and resource competition. However, dispersal increases the risk of predation and requires a great deal of energy that cannot be invested in other aspects of life history. As a consequence, dispersal in many organisms is limited to some individuals or to a brief time period, generally early in their life cycle (Roff 1990; Dingle and Holyoak 2001; Van Dyck and Baguette 2005; Hawkes 2009). Furthermore, in eusocial species, the production of dispersal units may be 
complicated by natural selection operating both at the individual and colony levels (Keller and Reeve 1999).

The queens of many ant species disperse as solitary individuals. In species undergoing independent colony foundation (hereafter, ICF), young virgin queens (hereafter, gynes) bear wings and fly away from their natal nest before mating. Shortly after copulation, they shed their wings and search for a suitable nest location in which to initiate their colony. A major advantage of ICF is that it enhances dispersal distance and allows for the production of many relatively cheap propagules. The main drawback is the extreme weakness of incipient colonies facing predation and competition (Wiernasz and Cole 1995; Gordon and Kulig 1998; Adams and Tschinkel 2001; Wiernasz and Cole 2003; Boulay et al. 2007). Alternatively, dependent colony foundation (DCF) or colony fission has evolved independently in numerous species (Peeters and Ito 2001). Here, some workers leave their natal nest to help young queens during foundation. In theory, this investment greatly increases propagule success but inevitably limits their number. However, until recently, colony fission has not been studied in depth, and data on propagule size and number are only available for a handful of species (Briese 1983; Lenoir et al. 1988; Bolton and Marsh 1989; Leal and Oliveira 1995; Fernández-Escudero et al. 2001).

Comparisons between congeneric species that utilize either ICF or DCF show that this transition entails important modifications in queens' physiology, morphology, and behavior (Bolton 1986; Heinze 1989; Keller and Passera 1989; Passera and Keller 1990; Lachaud et al. 1999; Howard 2006; Molet et al. 2007a, b; Molet et al. 2008; Foitzik et al. 2010). In species undergoing ICF, gynes accumulate important fat reserves and bear large wings (macroptery) operated by hypertrophied thoracic muscles. Their mesonotum, the second thoracic segment on which the wings are attached, is particularly developed. By contrast, in species undergoing DCF, gynes have a relatively undifferentiated thorax and are either short-wing (brachypters) or entirely wingless ergatoids. Both queen morphs have a spermatheca and well-developed ovaries, but the latter are morphologically very similar to workers (Peeters 1991; Tinaut and Ruano 1992; Heinze 1998). Because neither brachypters nor ergatoids are able to fly, they cannot join males during a nuptial flight. Instead they attract them to the ground by means of pheromones emitted during "sexual calling" behavior (Hölldobler and Haskins 1977).

The evolutionary processes leading to the reduction of queen size are not clear. Some authors implicitly suggest that the evolution of ergatoids occurs through selection acting at the colony level. In a recent review, Peeters and Molet (2009) stated that "the evolution of ergatoid queens corresponds to a strategy of colonial economy, because per capita costs of gynes are reduced (...) before and after adult emergence." This reasoning is based on the fact that the energy saved by workers in producing smaller queens can be invested in colony growth or in rearing males, which indirectly increases colony efficiency. In that case, both brachypters and ergatoids would result from the same evolutionary pathway, but the latter would represent a step further in the process of queen miniaturization.

On the other hand, larval selfish strategy has seldom been considered as a process favoring the evolution of small queens. In theory, a larva may expect a greater direct fitness by developing into a queen who will have her own offspring rather than by developing into a sterile worker (Bourke and Ratnieks 1999; Ratnieks 2001; Wenseleers and Ratnieks 2004). However, workers are expected to restrict the production of gynes, for example by limiting larval food intake. If queen size is not determinant for foundation, then natural selection operating at the individual level may favor a selfish strategy allowing worker-size gynes to develop in spite of the whole colony interest. Evidence for this conflict between workers and larvae first came from parasitic ants. Parasitic queens are generally smaller than their host queens, thus reducing the power of host workers to limit their production (Nonacs and Tobin 1992; Aron et al. 1999; Hora et al. 2005). Recently, a selfish larval strategy has been proposed in the stingless bee Schwarziana quadripunctata (Ratnieks 2001; Wenseleers et al. 2003, 2005 but Jarau et al. 2010). In this species, which undergoes colony fission, numerous larvae develop into dwarf queens while, from a worker perspective, only a few would be necessary to ensure colony reproduction. It has been suggested that these dwarf queens are selfish individuals that escape worker control and are produced at the cost of their mother colony (Ratnieks 2001; Wenseleers et al. 2003, 2005).

The aim of our study was to elucidate the role of individual- and colony-level selections in the evolution of ergatoid queens in ants. Our model species, Cataglyphis floricola, disperses by colony fission only. It constitutes an interesting model system since, as we will show here, strictly monogynous colonies can be headed either by a brachypter or by an ergatoid queen. First, we characterized the morphology of both queen morphs and compared worker-queen polymorphism in C. floricola with that of its nearest related species Cataglyphis emmae, which undergoes ICF (Délye 1968). Second, we tested alternative hypotheses regarding the evolution of ergatoids. If they correspond to a colony strategy, their production should save a substantial amount of energy while conserving an important reproductive potential. To that end, we compared brachypter and ergatoid individual fresh weights (energy costs for the colony) and ovariole numbers (potential benefits for the colony). We also analyzed the process of colony fission and the production and survival of both ergatoid and brachypter gynes in mother and daughter 
nests. Finally, we provide extensive field data on the process of colony fission.

Materials and method

Ant collection and study site

C. floricola is a thermophilic ant recently discovered in arid sandy areas of southwest Spain, near the estuary of the Guadalquivir river (Tinaut 1993). Molecular data suggest that the two color morphs initially described in this species (red and black) may constitute different species or subspecies (Amor, unpublished data). The present study was conducted on the red morph exclusively. Between 2007 and 2010, we randomly excavated 79 colonies during the whole period of activity (from early April to late October) in an open scrubland of the Biological Reserve of the Doñana National Park. In addition, 34 mother colonies and their respective daughter colonies were excavated during the reproduction period (late June-mid July).

C. emmae inhabits the pre-Saharan steppes of Morocco and Algeria (Forel 1909). Morphological data indicate that it is the closest known ancestor of C. floricola (Tinaut 1993; Tinaut 2009, personal communication). This conclusion has been reinforced by aphylogenic analysis of 12 Iberian and Moroccan Cataglyphis species based on mitochondrial DNA (Jowers, unpublished data). We collected 16 colonies of $\mathrm{C}$. emmae $10 \mathrm{~km}$ north of the village of Amerzgane, near Ouarzazate (Morocco) in May 2009, during their reproductive period.

\section{Worker-queen polymorphism}

All excavated nests were transferred to the laboratory to determine the presence of queens and gynes. Although ergatoids and workers are very similar in size, the former have a clearer thorax and more extended abdomen which allows a trained observer to spot them rapidly. Morphological measurements including inter-ocular distance, thorax length, pronotum width, mesonotum width and length, epinotum width, and left hind leg femur and tibia length were carried out on 18 brachypters, 32 ergatoids, and 36 workers of C. floricola and eight gynes and ten workers of C. emmae using a Zeiss Discovery V8 stereomicroscope connected to an AxioCam MRC5 digital camera. The fresh weight of five to ten individuals per caste and species was also measured to the nearest $10^{-1} \mathrm{mg}$.

Three individuals of each caste of $\mathrm{C}$. floricola were used for scanning electron microscopy of the thorax external structure and for comparison of thoracic musculature using the procedure described by Billen (2009). We also checked for the presence/absence of tegulae on ergatoids, brachyp- ters, and workers thorax. This criterion was further used to rapidly identify ergatoids among the workers. Finally, the reproductive potential of each caste of C. floricola was assessed by counting the number of ovarioles, determining the presence of yellow bodies and oocytes in formation and determining the presence of a spermatheca in 36 workers, nine ergatoid queens, and eight brachypter queens.

\section{Colony fission}

The process of colony fission was studied in C. floricola in 2008, 2009, and 2010. All the nests of three $100 \times 5-\mathrm{m}$ transects were mapped in May of each year and monitored approximately once a week during the following 2 months. The observation of social transports between two nests denoted the occurrence of colony fission. The distance between mother and daughter nests was measured systematically. Additional information on the frequency and duration of social transports during colony fission was obtained by video tape recording of seven nest entrances during a total of $10.7 \mathrm{~h}$.

Once social transports were no longer observed (34 days), both mother and daughter nests were excavated and taken to the laboratory to determine how adults and brood were segregated. Female cocoons of each nest were separated according to their size (small vs medium; Electronic appendix E.2; large cocoons contained males) and kept with a group of ten workers (larvae and cocoons produced after nest collection were not considered). Emergences were then recorded daily for 1 month to determine the number of ergatoids and brachypters produced in mother and daughter nests.

To determine their fate after emergence, gynes were returned to their colony of origin (either daughter or mother nest) no later than $24 \mathrm{~h}$ after emergence. Their survival was then monitored during the following 2 weeks.

\section{Statistical analyses}

All statistics were conducted using $\mathrm{R}$ software ( R Development Core Team 2010). Queen and worker weights were compared between species by means of ANOVA with TukeyHSD post-hoc test. Linear discriminant analysis was employed to test for morphological differences within and between workers and queens of C. floricola and C. emmae. In addition to the measurements described above, the proportion of the mesonotum of the thorax total length was included in the analysis. The significance of differences between castes and species was assessed for each trait by multivariate analysis of variance (MANOVA) and Pillai trace.

The segregation of adults and brood during fission was analyzed by fitting general mixed linear models (lme). 
Worker, cocoon, and gyne numbers were compared between daughter and mother nests (fixed effect). Other fixed effects for the number of cocoons and the number of gynes were cocoon size (medium vs small) and gyne morph (ergatoid vs brachypter), respectively. We also compared the proportion of ergatoids that emerged from small cocoons in daughter and mother nests. For gyne survival, we compared the number of gynes still alive after 15 days in mother and daughter colonies in function of their morph (ergatoid vs brachypter) and the number of gynes that were produced. In all lme, original nest identity was included as a random effect. Variables were log-transformed when necessary to approach normality. All statistical estimates are means $\pm \mathrm{SE}$.

\section{Results}

\section{Worker-queen polymorphism}

Figure 1 shows the three female castes of C. floricola, including workers (Fig. 1a), ergatoids (Fig. 1b), and brachypters (Fig. 1c). Out of the 79 nests of C. floricola that were excavated randomly between 2007 and 2010, 36 (46\%) contained a dealated brachypter queen, 32 (40\%) contained an ergatoid queen, and 11 (14\%) had no queen (queenless). The number of workers per colony $(187 \pm 15)$ did not differ significantly between the three types of nests (ANOVA: $F_{2,76}=2.87, p=0.0632$ ). In the field, three matings were observed, one involving a brachypter gyne and two involving ergatoid gynes (Electronic appendix E.1). Moreover, ergatoid and brachypter dissections confirmed their reproductive status. Contrarily to workers, both ergatoids and brachypters systematically presented a spermatheca and active ovarioles with oocytes in formation and

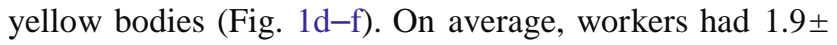
0.2 ovarioles that did not present oocytes in formation or yellow bodies. Ergatoids had significantly more ovarioles than workers (Fig. 1d; 11.8 \pm 1.2 , ANOVA: $\mathrm{F}_{2,50}=259.0, \mathrm{p}<$ $\left.0.001, \mathrm{t}_{50}=7.7, \mathrm{p}<0.0001\right)$ but significantly less than brachypters $\left(19.9 \pm 1.6, \mathrm{t}_{50}=-12.2, \mathrm{p}<0.0001\right)$. Longitudinal sections of the thorax indicated that in C. floricola workers, ergatoids and brachypters lacked prominent thoracic musculature (Fig. 1g-i), thus confirming that the latter are unable to fly. After their wings have been shed, four conspicuous tegulae remain on the mesothorax of brachypters (Fig. 1j-l). Although they are strictly wingless, ergatoids also present two, and rarely four, tiny tegulae.

All 16 colonies of $C$. emmae contained a dealated macropter queen and a total of 46 macropter gynes (Electronic appendix E.1). Morphological measurements of worker and queen heads, thorax, and legs indicated that worker-queen polymorphism was much more pronounced in C. emmae than in C. floricola (Table 1). The first discriminant function, which explained $90.8 \%$ of the total variance, was correlated with the length and width of the mesonotum. It separated macropter queens of C. emmae from the workers of both species and from the ergatoids of C. floricola (Fig. 2). Brachypters of C. floricola occupied an intermediate position. MANOVA confirmed these results (Table 1; Pillai trace $=4.10, \mathrm{~F}_{36,396}=15.4, \mathrm{p}<0.001$ ) and showed that the thorax of C. floricola brachypters, and particularly their mesonotum, was significantly smaller than that of $\mathrm{C}$. emmae queens. Ergatoid thoraces were more similar to those of the workers than to those of brachypters. Notably, in C. floricola, both ergatoids and brachypters had shorter legs than workers.

Workers and gynes fresh weight also differed significantly between both species (ANOVA: $\mathrm{F}_{4,27}=117.7, \mathrm{p}<$ $0.001)$. Although workers weighed about the same $(4.2 \pm$ $1.1 \mathrm{mg}$ vs $4.6 \pm 0.4 \mathrm{mg}$ for C. emmae and C. floricola, respectively; TukeyHSD, $\mathrm{p}=0.995)$, gynes of $\mathrm{C}$. emmae were 3.5-fold and 6-fold heavier than the brachypter and ergatoid gynes of C. floricola, respectively $(22.4 \pm 0.6$ vs $6.5 \pm 0.2$ and $3.7 \pm 0.3 \mathrm{mg}$, respectively; TukeyHSD, $\mathrm{p}<$ 0.001). Among C. floricola, the difference of weight between ergatoid and brachypter gynes was significant (TukeyHSD, $\mathrm{p}<0.037$ ). By contrast, ergatoids were not significantly lighter than workers (TukeyHSD, $\mathrm{p}<0.825)$.

\section{Colony fission and caste segregation in C. floricola}

Thirty-four colony fissions were observed between 2008 and 2010. Mother and daughter nests were separated by $7.7 \pm 0.9 \mathrm{~m}$ on average (range, 1.9 to $28.4 \mathrm{~m}$ ). All but two colonies produced only one daughter nest. Videotape recordings showed that during fission, ants carried out $20.17 \pm 4.04$ social transport events per hour (i.e., approximately one transport every $3 \mathrm{~min}$ ). Transporters ran very fast between the mother and the daughter nests $(1.33 \pm 0.09 \mathrm{~m} / \mathrm{min})$. Upon the arrival of a transporter at the daughter nest, an ant, probably the same individual, immediately came out and returned straight to the mother nest, suggesting that only a few workers were actually involved in numerous successive social transports.

Nest excavations indicated that mother nests contained significantly more workers than daughter nests (196 \pm 20 vs $99 \pm 7$ adult workers, respectively; lme: $t_{35}=4.99, p<$ 0.0001). Ten mother colonies (29\%) were headed by a dealated brachypter queen, 16 (47\%) were headed by an ergatoid queen, and eight (24\%) apparently had no queen. By contrast, one daughter nest (3\%) had a dealated brachypter queen, five (14\%) had an ergatoid queen, and 30 (83\%) were queenless (Pearson Chi square test: $\mathrm{X}_{2}{ }^{2}=$ 25.8, $\mathrm{p}<0.0001)$. In all cases in which no queen was found in a mother nest, no queen was discovered in the respective 

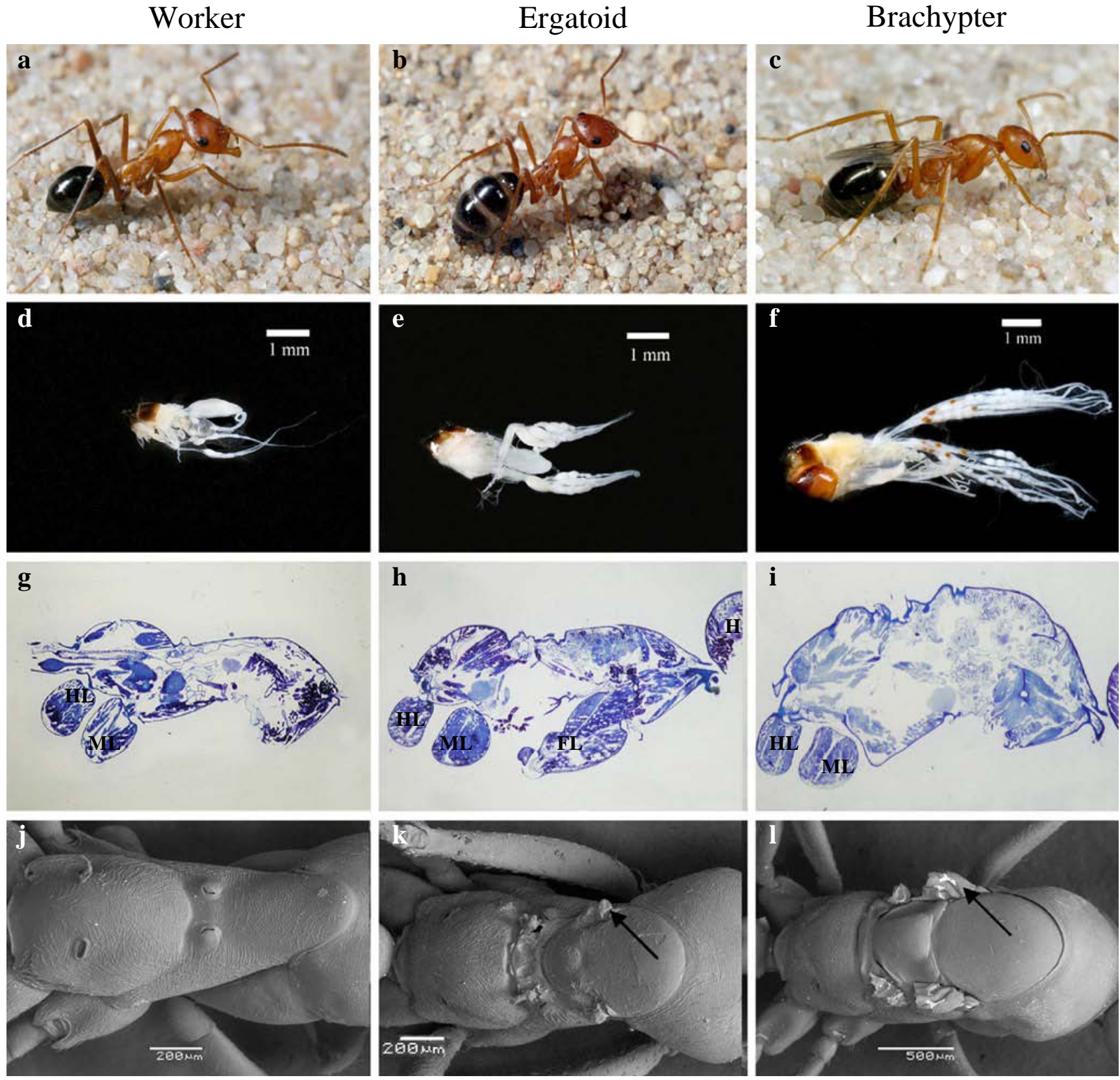

Fig. 1 Morphological differentiation between workers, ergatoids, and brachypters. a-c Entire view of each morph. Note the large thorax and short wings on the brachypters. The extended abdomen of the ergatoid does not allow her to be spotted in the colony as various workers can also present physogastry. $d-f$ Reproductive apparatus; the yellow bodies on the long ovarioles of the brachypter denote recent egg laying. g-i Internal morphology of the thorax (HL hind leg, ML mid leg, FL front leg, $\mathrm{H}$ head). $\mathrm{j}-\mathrm{l}$ External view of the thorax in SEM. Arrows indicate the position of the tegulae. Although the ergatoid presented here has four tegulae, most individuals only have two daughter nest either. This suggests that the mother queen generally remained in the original nest with about $70 \%$ of the workers whereas the gynes that emerged after the fission came from the cocoons that had been transported to the daughter nest, with about $30 \%$ of the workers.

Female cocoons were segregated between mother and daughter nests according to their size (E2; lme: $\mathrm{F}_{1,103}=$ 73.6, $\mathrm{p}<0.0001$ ). More small cocoons (volume, $6-18 \mathrm{~mm}^{3}$; see Electronic appendix E.2) remained in the mother nests than were transported to the daughter nests (Fig. 3a; $\mathrm{t}_{103}=$ 8.8, $\mathrm{p}<0.0001)$. In contrast, medium size cocoons (26$33 \mathrm{~mm}^{3}$ ) were significantly more numerous in daughter nests (Fig. 3a; $t_{103}=3.3, p=0.0013$ ). By isolating these cocoons immediately following nest excavation, we could monitor the caste of the emerging individuals. This revealed that both ergatoids and workers emerged from small 
Table 1 Morphological measurements of C. floricola and C. emmae

\begin{tabular}{|c|c|c|c|c|c|c|c|c|c|}
\hline \multirow[b]{2}{*}{ Traits } & \multirow[b]{2}{*}{ LD1 } & \multirow[b]{2}{*}{ LD2 } & \multicolumn{3}{|l|}{ C. floricola } & \multicolumn{2}{|l|}{ C. emmae } & \multirow[b]{2}{*}{$\mathrm{F}_{4,104}$} & \multirow[b]{2}{*}{$\mathrm{P}$} \\
\hline & & & Workers & Ergatoids & Brachypters & Workers & Macropters & & \\
\hline $\begin{array}{l}\text { Inter-ocular } \\
\text { distance }\end{array}$ & 4.77 & 5.20 & $0.90 \pm 0.04$ (a) & $0.97 \pm 0.06$ (a) & $1.06 \pm 0.01$ (b) & $0.93 \pm 0.02$ (a) & $1.46 \pm 0.09$ (c) & 56.2 & $<0.001$ \\
\hline $\begin{array}{l}\text { Pronotum } \\
\text { width }\end{array}$ & 1.09 & -2.31 & $0.87 \pm 0.06$ (a) & $0.89 \pm 0.03$ (a) & $1.09 \pm 0.06$ (b) & $0.87 \pm 0.02(\mathrm{a})$ & $1.49 \pm 0.07$ (c) & 92.9 & $<0.001$ \\
\hline $\begin{array}{l}\text { Mesonotum } \\
\text { width }\end{array}$ & 19.93 & -7.86 & $0.39 \pm 0.01(\mathrm{a})$ & $0.52 \pm 0.01(b)$ & $0.86 \pm 0.02$ (c) & $0.43 \pm 0.01$ (a) & $1.54 \pm 0.04$ (d) & 373.6 & $<0.001$ \\
\hline $\begin{array}{l}\text { Epinotum } \\
\text { width }\end{array}$ & -1.75 & 2.19 & $0.55 \pm 0.03$ (a) & $0.59 \pm 0.03$ (a) & $0.78 \pm 0.02$ (b) & $0.58 \pm 0.01$ (a) & $1.19 \pm 0.04(\mathrm{c})$ & 108.9 & $<0.001$ \\
\hline Thorax length & -5.19 & -18.64 & $1.84 \pm 0.03$ (a) & $1.87 \pm 0.03$ (a) & $2.28 \pm 0.03$ (b) & $1.76 \pm 0.06$ (a) & $2.93 \pm 0.11$ (c) & 83.9 & $<0.001$ \\
\hline $\begin{array}{l}\text { Mesonotum } \\
\text { length }\end{array}$ & 16.24 & 43.34 & $0.57 \pm 0.02$ (a) & $0.75 \pm 0.03$ (b) & $1.29 \pm 0.06$ (b) & $0.60 \pm 0.03$ (a) & $2.09 \pm 0.03$ (c) & 190.8 & $<0.001$ \\
\hline $\begin{array}{l}\text { Mesonotum/ } \\
\text { thorax }\end{array}$ & -0.27 & -0.94 & $0.33 \pm 0.07$ (a) & $0.40 \pm 0.02$ (b) & $0.56 \pm 0.03$ (c) & $0.32 \pm .0 .07$ (a) & $0.70 \pm 0.02$ (d) & 106.3 & $<0.001$ \\
\hline Femur length & -3.04 & 5.79 & $1.88 \pm 0.02$ (c) & $1.71 \pm 0.03$ (a) & $0.68 \pm 0.02(a b)$ & $1.62 \pm 0.04$ (b) & $1.95 \pm 0.09$ (c) & 5.1 & $<0.001$ \\
\hline Tibia length & 1.94 & -1.04 & $1.84 \pm 0.04$ (c) & $1.71 \pm 0.02$ (b) & $1.70 \pm 0.02$ (b) & $1.59 \pm 0.08$ (a) & $1.93 \pm 0.10(\mathrm{~d})$ & 8.1 & $<0.001$ \\
\hline
\end{tabular}

Mesonotum/thorax is the proportion of the mesonotum length from total thorax length. LD1 and LD2 are the linear discriminant coefficients of each variable. The $\mathrm{F}$ and $\mathrm{p}$ values are the results of the MANOVA. Different letters indicate significant differences

cocoons while brachypters only emerged from medium size cocoons (E2).

Monitoring of cocoon emergence also indicated that there was a general overproduction of ergatoids compared to brachypters. On average, each fissioning colony produced $2.4 \pm 0.5$ ergatoid gynes and $0.74 \pm 0.2$ brachypter gynes (lme: $\mathrm{F}_{1,103}=19.5, \mathrm{p}<0.0001$ ). However, the number of brachypter and ergatoid emergences differed significantly between mother and daughter nests (Fig. 3b; lme: $F_{1,103}=14.8, p=0.0002$ ). Hence, $94 \%$ of the brachypters emerged in daughter nests and only $6 \%$ emerged in mother nests ( $1.4 \pm 0.4$ vs $0.1 \pm 0.1$, respectively; $t_{103}=3.4$, $\mathrm{p}=0.0009$ ). The opposite was true for ergatoids; $69 \%$ of them emerged in mother nests and only $31 \%$ emerged in daughter nests ( $3.5 \pm 1.0$ vs $1.6 \pm 0.4$, respectively; $\mathrm{t}_{103}=2.0$, $\mathrm{p}=$ $0.0474)$. Yet, the proportion of ergatoids that emerged from the small cocoons was higher in daughter than in mother nests $\left(19 \%\right.$ vs $5 \%$; lme $\left.\mathrm{F}_{1,35}=5.6, \mathrm{p}<0.0237\right)$. This suggests that workers clearly identified brachypter cocoons and almost systematically transported them to the daughter nests. Although they were further able to distinguish between cocoons containing ergatoids versus workers, a majority of the latter remained and emerged in the mother nest, which also contained the mother queen.

Gyne fate in mother and daughter nests of C. floricola

Gyne fate during the 15 days after emergence differed if they were reintroduced into the mother or the daughter nest. The results of the first general linear mixed model that included all factors and first-order interactions indicated that the number of gynes that survived, irrespective of their caste, was significantly lower in mother than in daughter nests (Fig. 3c; lme: $\mathrm{F}_{1,18}=4.5, \mathrm{p}=0.01$ ) but did not depend on the number of gynes produced (lme: $F_{1,16}=0.1, p=0.76$ ) nor on whether they were ergatoids or brachypters (lme:
Fig. 2 Results of linear discriminant function analyses conducted on the nine morphological traits (see Table 1). Bf, Ef, and Wf: brachypters, ergatoids, and workers of C. floricola, respectively. Me and We: macropters and workers of C. emmae, respectively

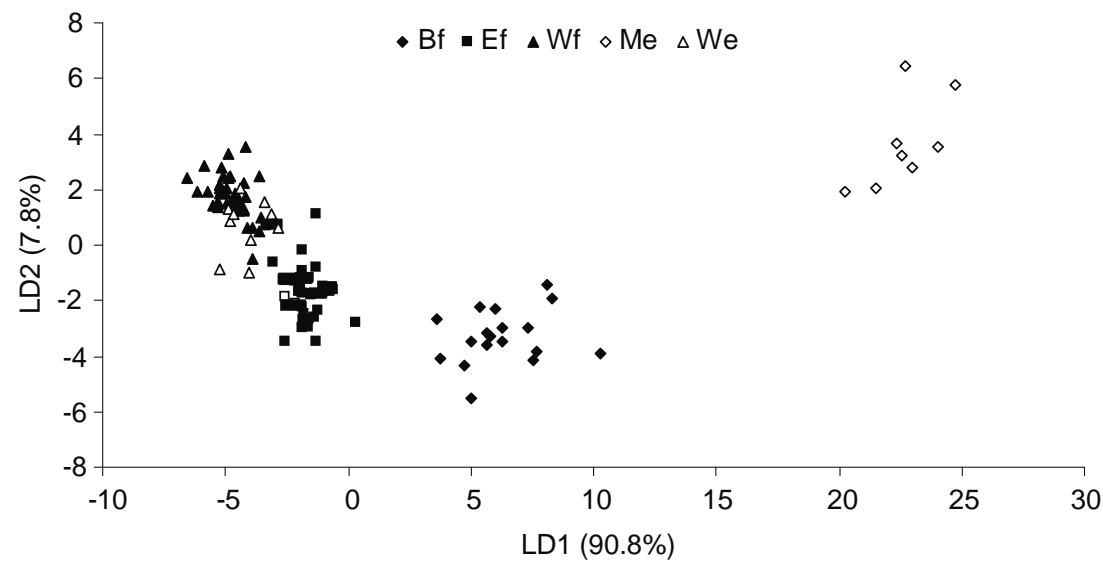


Fig. 3 The process of colony fission in C. floricola. a Segregation of cocoons according to their size between mother and daughter nests. b Number of gynes emerging in mother and daughter nests. c Gyne survival. Gynes emerged from cocoons collected in the field and reared in orphaned laboratory groups. Note that for representation purpose, the number of small cocoons was divided by 10 . Different letters denote significant differences. Values are means $\pm \mathrm{SE}$
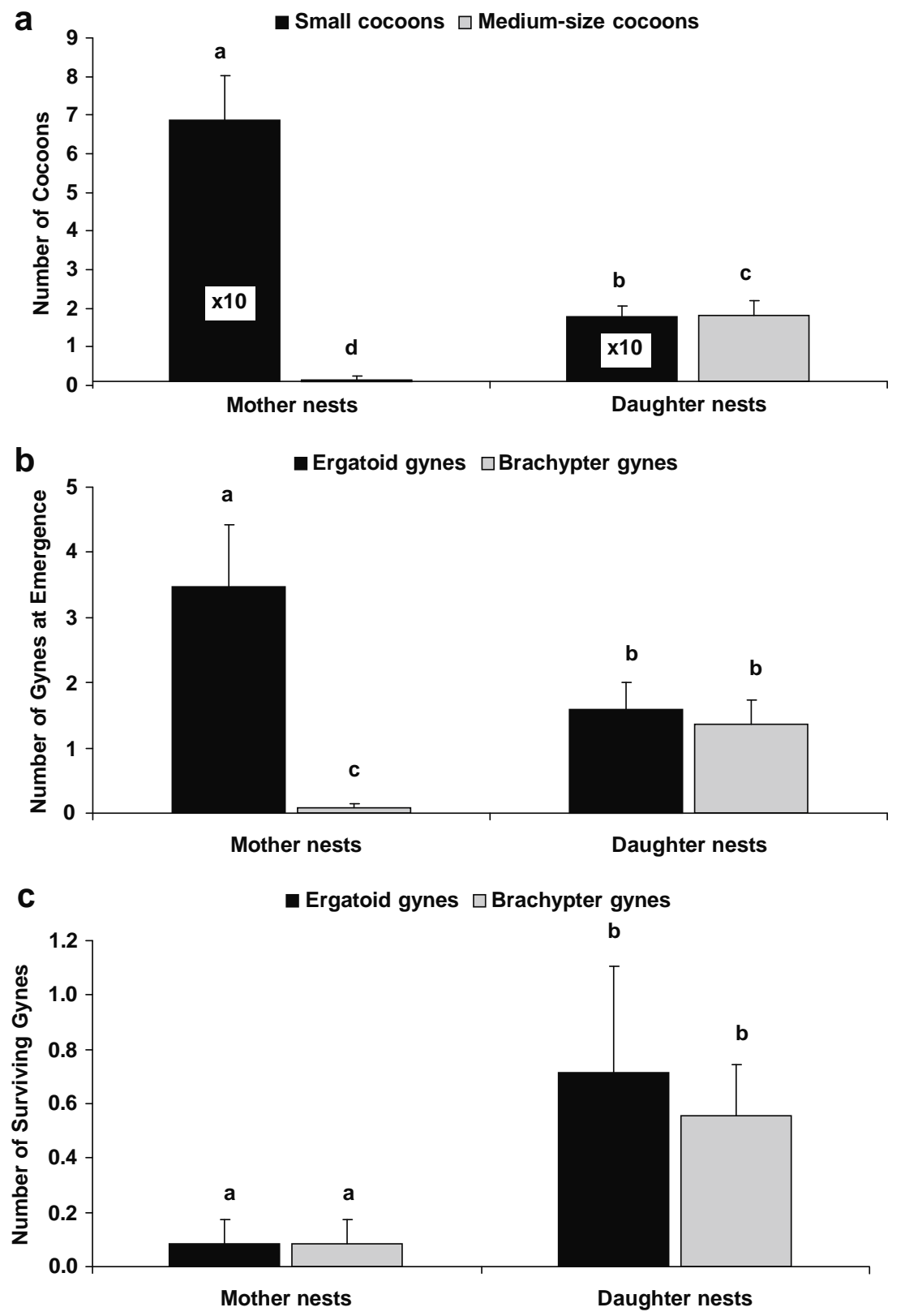

$\left.\mathrm{F}_{1,16}=0.12, \mathrm{p}=0.74\right)$. In daughter nests, $0.6 \pm 0.2$ and $0.7 \pm$ 0.4 ergatoids and brachypters survived, respectively, while only $0.1 \pm 0.1$ brachypters and ergatoids survived in mother nests. As a consequence, because more ergatoids were produced, their individual survival rate was significantly lower than that of brachypters $(0.05 \pm 0.03$ vs $0.34 \pm 0.10$; lme: $\left.F_{1,6}=7.1, p=0.04\right)$.

A second linear model, from which all non-significant effects had been removed, indicated that the average number of gynes that survived in the mother nests $(0.17 \pm$ $0.15)$ was not significantly different from $0(t=1.08, p=0.3)$ while the number of gynes that survived in daughter nests $(1.25 \pm 0.18)$ was not significantly different from $1(t=1.32$, $\mathrm{p}=0.2$ ). Although no fights among gynes or between the mother queen and the gynes were observed, workers were often seen biting the gynes just upon their reintroduction in their respective nests, suggesting that workers were responsible for gyne elimination.

Hence, to summarize on gyne fate, while all gynes (mostly ergatoids) that emerged in mother nests were systematically killed by workers, one gyne (either an ergatoid or a brachypter) survived in each daughter nest.

\section{Discussion}

In this study, we have shown that colonies of C. floricola are headed either by a brachypter or an ergatoid queen. 
Both are relatively small compared to C. emmae macropters. However, although brachypters have conserved several traits proper of ant reproductive caste (e.g., the wings), ergatoids are very similar to workers. By collecting extensive data on the process of colony fission, which has rarely been observed before, we determined that many ergatoids are eliminated by workers before they have the opportunity to compete for becoming new queens. Taken together, our results suggest that queen miniaturization in ants dispersing through colony fission, and notably the evolution of ergatoid queens, is unlikely to be the consequence of a colony-level strategy only.

The reduction of queen size between C. emmae and C. floricola is associated with a shift from ICF to DCF. A similar pattern has been reported in other comparative studies of congeneric species mostly in the subfamilies of Ponerinae (e.g., Mystrium, (Molet et al. 2007a), Odontomachus (Molet et al. 2007b), Rhytidoponera (Molet et al. 2008) and Myrmicinae (e.g., Monomorium (Bolton 1986), Leptothorax (Heinze 1989)). In a few species, macropters and small queens (either brachypters or ergatoids) co-exist and are associated to ICF and DCF, respectively (e.g., Ectatomma ruidum (Lachaud et al. 1999), Hypoponera opacior (Foitzik et al. 2010)). With DCF, several adaptations like strong thoracic musculature, long wings, and important fat reserves become useless and can progressively be lost. In the specific case of C. floricola, cocoons containing the gynes are transported during colony fission by single workers who seize them in their mandibles and carry them under their body. The production of large gynes as those of the size of C. emmae would probably increase transport time and, consequently, the risk of death by predation and heat shock, particularly in arid areas where ground temperature commonly exceeds $50^{\circ} \mathrm{C}$.

The occurrence of both brachypters and ergatoids in the same species is rare in ants. To our knowledge, it has so far been reported in one species only, Ephebomyrmex imberbiculus (Heinze et al. 1992). If the production of ergatoids were the result of a colony-level strategy, we would expect adult workers to get a higher indirect fitness by producing ergatoids rather than brachypters (Peeters and Molet 2009). However, several lines of evidence indicate that in C. floricola, the benefit for workers of producing ergatoids is limited. Ergatoids are, on average, $2.8 \mathrm{mg}$ lighter than brachypters, which is less than the weight of a single worker. Thus, the per capita economy for workers producing ergatoids instead of brachypters is quite small. On the other hand, ergatoids have half the number of ovarioles compared to brachypters. Therefore, their lifetime fecundity must be much lower, which also reduces the potential indirect fitness benefit gained by workers producing ergatoids instead of brachypters.
More importantly, ergatoids are produced in excess compared to brachypters, but their individual survival rate is lower. A large proportion (69\%) of the former emerge in the mother nests and are immediately killed by workers. By contrast, $94 \%$ of the brachypters emerge in daughter nests and can therefore compete for becoming a new queen. Because of the short time between fission and nest excavation (3-4 days), all ergatoid and brachypter cocoons most likely started their development in the mother nest, in the presence of the queen. Then, they were either transported to the daughter nest or remained in the mother nest. Although the workers that lead the fission were somehow able to discriminate ergatoid cocoons among the pool of worker cocoons, many of the latter remained in mother nests. The presence of the mother queen in the mother nest likely stimulated the elimination of all callow gynes by workers upon emergence. A similar phenomenon has been observed in Aphaenogaster senilis, in which it allows monogyny to be maintained (Boulay et al. 2009; Chéron et al. 2009; Cronin and Monnin 2009). Therefore, an important proportion of C. floricola ergatoids were killed without having any possibility of becoming queens, which represents a waste of energy for the colony that has reared them. By contrast, the cocoons of brachypters were perfectly segregated by the workers that participate in fission, probably on the basis of chemical and structural cues. Upon being transported to the daughter nest, they all had the opportunity to compete to become the new queen. How the new queen is chosen among the gynes that emerge in a daughter nest is not known, but it does not seem to depend on morphology. All but one gyne, either brachypter or ergatoid, were indeed eliminated by workers (no fights among gynes have been observed). Perhaps the first gyne to emerge, independently of its morph, has an advantage in this competitive process, as in A. senilis (Chéron et al. 2009; Cronin and Monnin 2009).

We propose a scenario in which the evolution of ergatoids results from an interplay between selections operating at the colony and individual levels. In species that found new colonies by fission, foundation is secured compared to ICF, but the number of possible propagules is drastically limited. In C. floricola, each propagule contains about $30 \%$ of the workers (around $343 \mathrm{mg} /$ propagule) and $21 \%$ of the cocoons of the mother colony. By comparison, in C. emmae, each gyne only weighs $22 \mathrm{mg}$ on average. In a strictly monogynous species like C. floricola, there is no benefit for adult workers to produce numerous gynes. Thus, colony-level selection should favor workers that invest most of the resources in the production of other workers (or males) and limit gyne production (Pamilo 1991). Nevertheless, a larva perspective can be slightly different. By developing into queen, she can have her own offspring while, by developing into worker, she will only have 
indirect fitness through the rearing of sisters (Bourke and Ratnieks 1999; Ratnieks 2001; Wenseleers et al. 2003). This difference in fitness expectations may be sufficient for natural selection to favor a selfish larval strategy. The mechanism of caste determination in C. floricola is not known. As in the majority of ants, the development of a larva into gyne probably depends on a variety of genetic and environmental factors (Schwander et al. 2010). However, the fact that ergatoids are only slightly larger and not heavier than workers reduces the ability of adult workers to enforce larval caste fate through differential feeding.

Except for their behavior and two tegulae, ergatoids are difficult to spot among the workers, which explains why they were unnoticed in previous studies (Tinaut 1993). Interestingly, the legs of both ergatoids and brachypters are quite similar and shorter than those of workers. In thermophilic Cataglyphis ants, long legs procure an ecological advantage by reducing workers' body exposure to extreme ground temperature (Cerdá and Retana 2000; Clémencet et al. 2010). Queens are always assisted by workers and almost never leave their nest, which explains why they may not need such an adaptation.

Our study also provides new extensive data on the process of colony fission. Mostly fortuitous results in other species so far indicate a great variety of processes. A detailed study in Proformica longiseta suggests that about $23 \%$ of the workers leave the mother colonies during fission (Fernández-Escudero et al. 2001), which is close to what we observed in C. floricola (30\%). Like in C. floricola, social transports in P. longiseta were performed by a few individuals and most queens (P. longiseta is polygynous) remained in the mother nest. In C. floricola, colony fission occurs before the emergence and mating of the new queen like, for example, in the honeybee (Seeley 1995). However, this differs from what is known in the congeneric species Cataglyphis cursor in which gynes emerge in the old nest, mate, and then are transported by workers to the new nest. Moreover, in C. cursor, a mother colony frequently gives rise to several daughter nests while multiple fissions are very rare in C. floricola.

The shift from ICF to DCF is an important step that reduces the selective advantage of large queens and reduces worker control on caste determination through differential feeding. Therefore, as in the case of the stingless bee $\mathrm{S}$. quadripunctata (Ratnieks 2001; Wenseleers et al. 2005), DCF may set the stage for the expression of a selfish larval strategy. Further studies should estimate and compare the colony- and individual-level benefits of producing ergatoids and brachypters in other species known to have both queen morphs, such as E. imberbiculus (Heinze et al. 1992). Moreover, our understanding of the evolution of workerqueen polymorphism will require advances in the develop- mental biology of caste formation. Finally, an interesting question is whether the proportion of ergatoids and brachypters in C. floricola has reached an equilibrium or if the former will eventually replace the latter as it possibly has happened in many other species.

Acknowledgments We thank D. Aragonés, Á. Barroso, A. Carvajal, T. Cerdá, M.Á Cobo, J. Melgar, L. Sinde, and C. Ruel for their help in the field and C. Vaquero for her assistance with the MEB. We are also grateful to C. Peeters, T. Wenseleers, T. Monnin, P. Nonacs, J. Pearce, and an anonymous referee for their helpful comments throughout this work. Jacqueline Minett assisted us with English editing. This project was funded by grants CGL2009-12472, CGL2006-04968, and CGL2009-09690 from the Spanish Ministerio de Ciencia e Innovación and Feder (for RB, $\mathrm{XC}$, and $\mathrm{AL}$ ). We thank the authority of the Doñana National Park for permitting access to research installations.

\section{References}

Adams ES, Tschinkel WR (2001) Mechanisms of population regulation in the fire ant Solenopsis invicta: an experimental study. J Anim Ecol 70:355-369

Aron S, Passera L, Keller L (1999) Evolution of social parasitism in ants: size of sexuals, sex ratio and mechanisms of caste determination. Proc R Soc Lond B 266:173-177

Billen J (2009) Occurrence and structural organization of the exocrine glands in the legs of ants. Arthropod Struct Dev 38:2-15

Bolton B (1986) Apterous females and shift of dispersal strategy in the Monomorium salomonis-group (Hymenoptera: Formicidae). J Nat Hist 20:267-272

Bolton B, Marsh AC (1989) The Afrotropical thermophilic ant genus Ocymyrmex (Hymenoptera: Formicidae). J Nat Hist 23:12671308

Boulay R, Cerdá X, Simon T, Roldan M, Hefetz A (2007) Intraspecific competition in the carpenter ant Camponotus cruentatus: should we expect the dear enemy effect? Anim Behav 74:985-993

Boulay R, Cerdá X, Fertin A, Ichinose K, Lenoir A (2009) Brood development into sexual females depends on the presence of a queen but not on temperature in an ant dispersing by colony fission, Aphaenogaster senilis. Ecol Entomol 34:595-602

Bourke AFG, Ratnieks FLW (1999) Kin conflict over determination in social hymenoptera. Behav Ecol Sociobiol 46:287-297

Briese DT (1983) Different modes of reproductive behavior (including a description of colony fission) in a species of Chelaner (Hymenoptera: Formicidae). Insect Soc 30:308-316

Bullock JM, Kenward RE, Hails RS (2002) Dispersal ecology. Blackwell Science, Malden

Cerdá X, Retana J (2000) Alternative strategies by thermophilic ants to cope with extreme heat: individual versus colony level traits. Oikos 89:155-163

Chéron B, Doums C, Federici P, Monnin T (2009) Queen replacement in the monogynous ant Aphaenogaster senilis: supernumerary queens as life insurance. Anim Behav 78:1317-1325

Clémencet J, Cournault L, Odent A, Doums C (2010) Worker thermal tolerance in the thermophilic ant Cataglyphis cursor (Hymenoptera, Formicidae). Insect Soc 57:11-15

Clobert J, Danchin E, Dhondt AA, Nichols JD (2001) Dispersal. Oxford University Press, New York

Cronin A, Monnin T (2009) Bourgeois queens and high stakes games in the ant Aphaenogaster senilis. Front Zool 6:24 
Délye G (1968) Recherches sur l'écologie, la physiologie et l'éthologie des fourmis du Sahara. In. Doctoral diss., Université d'Aix-Marseille

R Development Core Team (2010) R: A language and environment for statistical computing. R Foundation for Statistical Computing, Vienna, Austria. ISBN 3-900051-07-0. http://www.R-project.org. Accessed 16 Dec 2010

Dingle H, Holyoak M (2001) The evolutionary ecology of movement. In: Fox C, Roff DA, Fairbairn DJ (eds) Evolutionary ecology. Oxford University Press, New York, pp 247-261

Fernández-Escudero I, Seppä P, Pamilo P (2001) Dependent colony founding in the ant Proformica longiseta. Insect Soc 48:80-82

Foitzik S, Kureck IM, Ruger MH, Metzler D (2010) Alternative reproductive tactics and the impact of local competition on sex ratios in the ant Hypoponera opacior. Behav Ecol Sociobiol 64:1641-1654

Forel A (1909) Études myrmécologiques en 1909. Fourmis de Barbarie et de Ceylan. Nidification des Polyrhachis. Bull Soc Vaud Sci Nat 45:369-407

Gordon DM, Kulig A (1998) The effect of neighbours on the mortality of harvester ant colonies. J Anim Ecol 67:141-148

Hawkes C (2009) Linking movement behaviour, dispersal and population processes: is individual variation a key? J Anim Ecol 78:894-90

Heinze J (1989) Alternative dispersal strategies in a North American ant. Naturwissenschaften 76:477-478

Heinze J (1998) Intercastes, intermorphs, and ergatoid queens: who is who in ant reproduction? Insect Soc 45:113-124

Heinze J, Hölldobler B, Cover SP (1992) Queen polymorphism in the North American harvester ant, Ephebomyrmex imberbiculus. Insect Soc 39:267-273

Hölldobler B, Haskins CP (1977) Sexual calling behavior in primitive ants. Science 195:793-794

Hora RR, Doums C, Poteauc C, Fénéron R, Valenzuela J, Heinze J, Fresneau D (2005) Small queens in the ant Ectatomma tuberculatum: a new case of social parasitism. Behav Ecol Sociobiol $59: 285-292$

Howard KJ (2006) Three queen morphs with alternative nest-founding behaviors in the ant, Temnothorax longispinosus. Insect Soc 53:480-488

Jarau S, Van Veen JW, Twele R, Reichle C, Herrera Gonzales E, Aguilar I, Francke W, Ayasse M (2010) Workers make the queens in Melipona bees: identification of geraniol as a caste determining compound from labial glands of nurse bees. J Chem Ecol 36:565-569

Keller L, Passera L (1989) Size and fat-content of gynes in relation to the mode of colony founding in ants (Hymenoptera, Formicidae). Oecologia 80:236-240

Keller L, Reeve HK (1999) Dynamics of conflicts within insect societies. In: Keller L (ed) Levels of selection in evolution. Princton University Press, Princeton, pp 153-175

Lachaud JP, Cadena A, Schatz B, Pérez-Lachaud G, Ibarra-Núñez G (1999) Queen dimorphism and reproductive capacity in the ponerine ant, Ectatomma ruidum Roger. Oecologia 120:515523

Leal IR, Oliveira PS (1995) Behavioral ecology of the neotropical termite-hunting ant Pachycondyla (=Termitopone) marginata: colony founding, group-raiding and migratory patterns. Behav Ecol Sociobiol 37:373-383
Lenoir A, Querard L, Pondicq N, Berton F (1988) Reproduction and dispersal in the ant Cataglyphis cursor (Hymenoptera, Formicidae). Psyche 95:21-44

Molet M, Peeters C, Fischer B (2007a) Winged queens replaced by reproductives smaller than workers in Mystrium ants. Naturwissenschaften 94:280-287

Molet M, Peeters C, Fisher BL (2007b) Permanent loss of wings in queens of the ant Odontomachus coquereli from Madagascar. Insect Soc 54:183-188

Molet M, Van Baalen M, Peeters C (2008) Shift in colonial reproductive strategy associated with a tropical-temperate gradient in Rhytidoponera ants. Am Nat 172:75-87

Nonacs P, Tobin JE (1992) Selfish larvae: development and the evolution of parasitic behavior in the Hymenoptera. Evolution 46:1605-1620

Pamilo P (1991) Evolution of colony characteristics in social insects, I. Sex allocation. Am Nat 137:83-107

Passera L, Keller L (1990) Loss of mating flight and shift in the pattern of carbohydrate storage in sexuals of ants (Hymenoptera, Formicidae). J Comp Physiol B 160:207-211

Peeters C (1991) Ergatoid queens and intercastes in ants: two distinct adult forms which look morphologically intermediate between workers and winged queens. Insect Soc 38:1-15

Peeters C, Ito F (2001) Colony dispersal and the evolution of queen morphology in social Hymenoptera. Ann Rev Entomol 46:601-630

Peeters C, Molet M (2009) Colonial reproduction and life histories. In: Lach L, Parr C, Abbott K (eds) Ant ecology. Oxford University Press, Oxford, pp 161-178

Ratnieks FLW (2001) Heirs and spares: caste conflict and excess queen production in Melipona bees. Behav Ecol Sociobiol 50:467-473

Roff DA (1990) The evolution of flightlessness in insects. Ecol Monogr 60:389-421

Schwander T, Lo N, Beekman M, Oldroyd BP, Keller L (2010) Nature versus nurture in social insect caste differentiation. Trends Ecol Evol 25:275-282

Seeley T (1995) The wisdom of the hive: the social physiology of honey bee colonies. Harvard University Press, Cambridge

Tinaut A (1993) Cataglyphis floricola nov. sp. new species for the genus Cataglyphis Förster, 1850 (Hymenoptera, Formicidae) in the Iberian Peninsula. Mitt Schweiz Entomol Ges 66:123-134

Tinaut A, Ruano F (1992) Braquipterismo y apterismo en formícidos. Morfología y biometría en las hembras de especies ibéricas de vida libre (Hymenoptera: Formicidae). Graellsia 48:121-131

Van Dyck H, Baguette M (2005) Dispersal behavior in fragmented landscapes: routine or special movements. Bas App Ecol 6:535-545

Wenseleers T, Ratnieks FLW (2004) Tragedy of the commons in Melipona bees. Proc R Soc B 271:S310-S312

Wenseleers T, Ratnieks FL, Billen J (2003) Caste fate conflict in swarm-founding social Hymenoptera: an inclusive fitness analysis. J Evol Biol 16:647-658

Wenseleers T, Ratnieks FLW, MdF R, DdA A, Imperatriz-Fonseca VL (2005) Working-class royalty: bees beat the caste system. Biol Lett 1:125-128

Wiernasz DC, Cole BJ (1995) Spatial distribution of Pogonomyrmex occidentalis: recruitment, mortality and overdispersion. J Anim Ecol 64:519-527

Wiernasz DC, Cole BJ (2003) Queen size mediates queen survival and colony fitness in harvester ants. Evolution 57:2179-2183 